\title{
Genetic linkage and association studies of Type I diabetes: challenges and rewards
}

\section{L.Field}

Department of Medical Genetics, BC Research Institute for Children's and Women's Health, University of British Columbia, Vancouver, BC, Canada

\section{Abstract}

Family and twin studies have shown clearly that Type I (insulin-dependent) diabetes mellitus has a genetic basis. However, only within the past decade has it been possible to systematically attempt to identify the genes that increase susceptibility to this disorder using linkage and association analysis of genetic markers distributed across the genome. More than 20 putative diabetes-predisposing genes have been localised in addition to HLA region susceptibility genes detected more than 25 years ago. Unfortunately, the effects of most diabetes-predisposing genes are weak, with the exception of HLA region susceptibility genes (which contribute about half of the genetic risk). The overall effects of diabetes-predisposing genes could be weak because the susceptibility gene occurs in only a small proportion of diabetic patients or the susceptibility gene (although it might be com- mon) produces only a modest increase in risk, probably by acting in concert with other such genes to cause disease. The weak effects of these genes have made them difficult to locate, difficult to confirm in independent studies and difficult to isolate by genetic procedures. This paper summarizes the major challenges that have faced geneticists in mapping Type I diabetes genes, and reviews the progress achieved to date. The rewards of the genetic studies will be twofold: increased understanding of the causes of Type I diabetes, facilitating creation of preventative therapies, and enabling clinicians in the future to use genetic information to predict which children are predisposed to diabetes in order to target them for preventative therapies. [Diabetologia (2002) 45: 21-35]

Keywords Type I diabetes, aetiology, genetics, susceptibility genes, linkage, association.
Type I diabetes (formerly called insulin-dependent diabetes mellitus) results from the autoimmune destruction of the insulin-producing beta cells of the

Received: 25 April 2001 and in revised form: 25 July 2001

Corresponding author: L. L. Field, Department of Medical Genetics, BC Research Institute for Children's and Women's Health, University of British Columbia, 950 West 28 Ave., Vancouver, BC, V5Z 4H4, Canada, e-mail: llfield@interchange.ubc.ca

Abbreviations: MZ, Monozygotic; DZ, dizygotic; ICA, islet cell antibodies; IAA, insulin autoantibodies; GAD, glutamic acid decarboxylase; IA-2, protein tyrosine phosphatase-2; LADA, latent autoimmune diabetes in adults; MLS, maximum lod score statistic; AFBAC, affected-family-based controls; TDT, transmission disequilibrium test pancreas. It is now known that Type I diabetes is a genetically complex disease, i.e. a disease caused by multiple genes interacting with non-genetic (environmental and stochastic) factors. Family studies have clearly shown a genetic basis but inheritance of the disease does not follow a simple mendelian single-locus pattern. Population and family studies also suggest that most (perhaps all) affected individuals are genetically predisposed to Type I diabetes, particularly through HLA region genes. However, non-genetic factors appear to be required to precipitate the disease in these genetically susceptible persons because in monozygote (MZ) twin pairs in which one twin has Type I diabetes the MZ twin concordance rate is less than $100 \%$. It is not clear whether there are any purely genetic cases of Type I 
diabetes, in which non-genetic factors are unnecessary.

This review will focus on the more than 20 putative diabetes-predisposing genes identified by linkage and association (linkage disequilibrium) studies. Particular emphasis will be given to the challenges encountered in locating and confirming these genes. However, first we will review the general evidence that Type I diabetes has a genetic basis and summarise the two primary methods for finding genes predisposing to genetically complex disorders.

\section{Evidence for a genetic basis: family and twin studies of Type I diabetes}

What is the evidence that Type I diabetes has a genetic basis? The simplest evidence comes from the fact that the frequency of the disorder is higher in close relatives of diabetic patients than in the general population (note: the reference population in the discussion which follows are people of European ancestry, who have the highest prevalence of Type I diabetes). For example, the frequency of Type I diabetes in siblings of diabetics is about $6 \%$ by age 30 [1], while the frequency in the general population is about $0.4 \%$ by age 30 [2]. Thus, Type I diabetes is about $6 / 0.4$, i. e. 15 times more common in siblings of diabetic patients than in the general population. This ratio between frequency in siblings compared with the general population is referred to as $\lambda_{\text {sib }}$ [3] .

Children of Type I diabetic patients also have a higher frequency of diabetes, about 3-6\%. Interestingly, several studies have shown that the risk of diabetes in children is lower if the diabetic parent is the mother than if the diabetic parent is the father, eg. by 20 years of age, $1 \%$ compared with $6 \%$ [4], $3 \%$ compared with $9 \%$ [5], $4 \%$ compared with $8 \%$ [6]. Risk of diabetes-related autoantibodies without overt diabetes (see below) has also shown a parental-sex effect: children of diabetic mothers were positive for autoantibodies less often than those of diabetic fathers $[7,8]$. The reason for the sex-of-parent effect is not known, but could be due to genetic or non-genetic factors or both. Possibilities include, firstly, diabetes-prone fetuses of diabetic mothers could be miscarried more often than non-diabetes-prone fetuses; secondly, diabetes-prone fetuses of diabetic mothers could be protected against development of pancreatic autoimmunity and diabetes; and thirdly, diabetespredisposing genes could be less diabetogenic when inherited from mothers than when inherited from fathers (imprinting). One study has shown no relation between pre/perinatal death rates and frequency of diabetes in children of diabetic mothers, arguing against the selective loss mechanism [9]. Additional investigations are needed into this intriguing natural difference in diabetes risk for children of diabetic mothers compared with fathers, as it could suggest ways to artificially reduce the risk through medical intervention.

Because close relatives of diabetic patients share common environmental factors, it could be argued that shared environment alone accounts for the increased risk of Type I diabetes among relatives of diabetic patients. More definitive evidence for a genetic basis is obtained by comparing the diabetes concordance rates in monozygotic (MZ, 100\% shared genes) and dizygotic twins (DZ, average $50 \%$ shared genes), because twins experience similar environments both before and after birth. These studies have consistently shown a higher Type I diabetes concordance rate in MZ twins than DZ twins [10-13], demonstrating a clear genetic basis for this disorder. The MZ twin concordance rate also provides a rough idea of the degree of genetic compared with non-genetic determination in specific environments. This concordance rate has been variously estimated as $34 \%$ by age 30 [11], $43 \%$ within 12 years of diagnosis of the index case [14], and $50 \%$ within 40 years of index diagnosis [15], implying strong non-genetic factors (reflected as discordance) in the aetiology of Type I diabetes.

Age at onset of clinical disease could define subtypes of Type I diabetes influenced by different predisposing genes. Recently reported correlations for age at onset in diabetic MZ twins $(r=0.94)$ and diabetic non-twin siblings ( $r=0.53)$ suggest that most of the variability in onset age is genetically determined [16]. However, another recent study found a lower MZ concordance rate when the index was diagnosed at 25 years of age or older, suggesting a role for agerelated non-genetic factors [15]. Adults who present after 30 years of age with apparent non-insulin dependent diabetes, which later converts to insulin-dependency, could have latent autoimmune diabetes in adults (LADA) [17,18]. This slow-onset form of insulin-dependent diabetes is characterised by the presence of diabetes-related autoantibodies such as antiGAD (see below). However, the levels of such autoantibodies have been found to be lower than in patients with typical Type I diabetes, possibly reflecting a less aggressive autoimmunity [19]. Similarly, the frequency of high-risk HLA genotypes in LADA patients was lower than in Type I diabetics, but higher than in Type II diabetics who were negative for GAD autoantibodies [20]. Thus, LADA patients could have fewer or less potent Type I diabetes susceptibility genes, or they may have protective genes that retard progression of disease or both.

Because concordance rates in $\mathrm{MZ}$ twins are not $100 \%$, it is clear that non-genetic factors must also contribute to Type I diabetes. Non-genetic factors could include environmental agents, such as viruses [21] or cow's milk proteins [22], and also purely stochastic processes, operating (for example) during vi- 
rus innoculation and replication, during the development of the immune system (T-cell receptor and immunoglobulin rearrangement), or during growth of the pancreatic beta-cell mass. Evidence for viral involvement is particularly strong. For example, congenital rubella infection is associated with a dramatically increased risk of autoimmune diabetes [23]. Similarly, recent studies have shown higher frequencies of antibodies towards Coxsackie B enteroviruses in prediabetic children [24] and in mothers of such children at time of delivery [25], as well as temporal association between appearance of antiviral antibodies and diabetes-associated autoantibodies [26].

\section{Evidence for a genetic basis: studies of diabetes- associated autoantibodies}

Type I diabetes has a long preclinical phase during which $T$ cells infiltrate the islets of the pancreas, and autoantibodies to a variety of islet cell components are formed. This preclinical phase progresses to clinically overt disease when the majority of beta cells have been destroyed. Autoantibodies towards cytoplasmic islet cell antigens (ICA), insulin (IAA), glutamic acid decarboxylase (GAD), and protein tyrosine phosphatase-2 (IA-2) are common in patients at the time of diagnosis and in close relatives who subsequently become diabetic [7, 14]. It is not currently known whether these autoantibodies directly participate in beta-cell destruction by binding with beta-cell antigens, or whether they arise as a consequence of beta-cell destruction following release of self-antigens from destroyed beta cells [27]. Either way, the presence of antibodies to islet cell components (especially multiple autoantibodies at high titres) is strongly associated with risk of progressing to clinical diabetes, both in relatives of Type I diabetic patients [7] and in the general population [28]. Recent studies have shown that autoantibodies occur even in infants and young children who later develop diabetes, suggesting that the autoimmune process could begin very early in life, perhaps prenatally $[8$, $29,30]$. Because autoantibodies are biological markers for preclinical diabetes, it is important to know whether these autoantibodies show evidence for genetic determination, or whether they merely reflect the presence of non-genetic diabetes-predisposing factors (such as viruses that damage beta cells). In the general population, the frequencies of ICA, IAA, and anti-GAD are low - for example, 3-4\% in a study of Swedish children [31] and 2\% in a study of British children [28]. The frequencies among siblings of Type I diabetics are somewhat higher - for example, $6 \%$ of siblings were ICA + in one large study [32]. Again, because familial aggregation of autoantibodies could be due to shared environment, twin studies are required to establish a genetic contribu- tion. One research group found that among non-diabetic co-twins of Type I diabetic patients, the frequencies of ICA, IAA and anti-GAD were not higher in MZ co-twins $(20 \%, 50 \%, 40 \%$ for the three antibody types) than in DZ co-twins ( $26 \%, 49 \%, 40 \%)$, suggesting that islet cell autoimmunity is environmentally determined [33]. In contrast, another group found that ICA, IA-2, and anti-GAD were more frequent in non-diabetic $\mathrm{MZ}$ co-twins $(28 \%, 28 \%$, $22 \%$ for the three antibody types) than in non-diabetic DZ co-twins $(22 \%, 11 \%, 11 \%)$ [14]. Similarly, a third group detected higher frequencies of anti-islet antibodies among non-diabetic MZ co-twins (42\%) than among non-diabetic DZ co-twins $(20 \%)$, nondiabetic non-twin siblings $(11 \%)$, or unrelated control subjects $(6 \%)$ [34]. These results support both a genetic contribution (difference in autoantibody frequencies between MZ and DZ co-twins) and a nongenetic contribution (difference between $\mathrm{DZ}$ and non-twin siblings). Other investigations of non-diabetic MZ co-twins of diabetic twins have shown even higher frequencies of autoantibodies. For example, of 11 non-diabetic $\mathrm{MZ}$ co-twins of diabetic twins, $100 \%(11 / 11)$ had IAA in at least one of two blood samples taken at different times [35]. Similarly, another study found that of $12 \mathrm{MZ}$ co-twins of diabetic twins who had remained non-diabetic for 8-39 years, $66 \%(8 / 12)$ nevertheless had persistent autoantibodies or evidence of beta-cell damage or both [36]. The above data indicate that among relatives of Type I diabetic patients, subclinical signs of pancreatic autoimmunity could be more common than overt diabetes. It is reasonable to suppose that a subset of the genes which predispose to Type I diabetes in fact predispose specifically to this early islet cell autoimmunity. Identification of these genes could assist in designing therapies that intervene at the earliest stages of disease pathogenesis and prevent progression to clinical diabetes.

If the pathogenesis of diabetes begins in very early life (perhaps even prenatally), then the immune status of the mother during pregnancy could be as relevant as the immune status of her diabetes-at-risk offspring. If so, then elucidating the genetic basis of Type I diabetes will also require analysis of maternal genotype and maternal-fetal genotype interactions. Very few studies of this nature have been conducted. Furthermore, if viral infection is involved in the initiation of the autoimmune process, then genetic differences between individuals in immune response towards viruses could alter their predisposition to Type I diabetes.

\section{Methods for detecting susceptibility genes}

Family and twin studies, such as those described above, have concluded that Type I diabetes has a genetic basis. How, then, are the locations of the rele- 
Table 1. Comparison of linkage and association analysis for mapping genetically complex disorders

Linkage analysis
Tests for co-segregation of marker and disease locus alleles in
families.
Significant result indicates physical linkage between marker and
disease loci.
Requires family data with at least two affected children (with or
without parents).
Can detect disease locus even if it is not close to marker.

Fewer markers needed for genome scan.

Less powerful for detecting common disease susceptibility alleles of modest effect.

Association analysis

Tests for association between marker and disease locus alleles in population.

Significant result could indicate physical linkage with linkage disequilibrium between marker and disease loci (must exclude other causes of association, e.g. population stratification).

Can use population (case-control) or family data. Family data excludes stratification effects and needs only one affected child.

Can detect disease locus only if it is close to marker and if linkage disequilibrium exists.

Many more markers needed for genome scan.

More powerful for detecting common disease susceptibility alleles of modest effect. vant genes identified? The two primary methods are linkage analysis and association (linkage disequilibrium) analysis. These are distinct but complementary methods (see Table 1).

Linkage analysis. Linkage analysis is a method to determine whether there is evidence for co-segregation (due to physical linkage on a chromosome) of alleles at a hypothetical disease-susceptibility locus and alleles at a marker locus in families with multiple affected members. A marker locus is a DNA segment with sequence variation between individuals, which can be thought of as "marking" a chromosomal location. In classical parametric lod score linkage analysis, the probability of linkage between disease and marker loci is compared to the probability of no linkage, and the log of this odds ratio is taken to derive the lod (log of odds) score. It is conventional to require a maximum lod score of 3.0 or greater to claim that evidence for linkage is significant. However, because linkage studies of genetically-complex diseases such as Type I diabetes frequently involve genome scans, it has been recommended that a higher lod score of 3.3 be required (to compensate for the large number of markers tested, which increases the probability of false positive results) [37]. As we will see below this criterion has often been difficult to achieve in actual studies. To do parametric linkage analysis, the researcher must specify an inheritance model for the hypothetical disease locus, including parameters such as penetrances for each genotype and the disease allele frequency. When these parameters can be accurately estimated (eg. for a single-locus mendelian disorder), lod score analysis is the most powerful method for disease gene localisation. However, these parameters are unknown for one susceptibility locus in a multigene disease, therefore so-called model-independent methods have been advocated for linkage analysis of these disorders. The most common model-independent method is affected sibpair linkage analysis, in which pairs of siblings who are both affected with the disorder are genotyped to determine their average proportion of alleles shared at each marker locus. If the marker allele sharing is significantly greater than the $50 \%$ sharing expected by chance in siblings, this indicates that the region containing the marker locus also contains a disease susceptibility locus. A maximum lod score equivalent (called an MLS) can be constructed from the observed sharing data [38].

Association analysis. Association analysis is a method to determine whether particular marker alleles are more frequent in people with disease than in control subjects. If an association is found between the disease and particular marker alleles, this is considered to be due to linkage with linkage disequilibrium between the disease and marker loci. Linkage disequilibrium exists when allele combinations at the linked disease and marker loci are found in non-random proportions in the population (i.e. the disease allele is found more or less often than expected with particular marker alleles). It results from very close linkage $(<1 \mathrm{cM})$ and insufficient evolutionary time since new alleles arose for randomisation of combinations to have been reached by chromosomal crossing over. Association means that particular marker alleles tend to occur with disease across the entire population (different families have the same marker alleles co-occurring with disease), while linkage means only that particular marker alleles occur (co-segregate) with disease within each family (different families can have different marker alleles segregating with disease). Because linkage disequilibrium exists only over small chromosomal distances, a marker very close to the disease locus has to be tested to detect association. Conversely, finding significant association implies not only that the marker is linked to the disease locus, but also that the marker is very closely linked to the disease locus. In traditional case-control (population-based) tests of association, marker allele or genotype frequencies in unrelated patients and unrelated control subjects are compared. However, if control subjects are not ethnically matched to cases, 
spurious (false positive) association can result. While this is not a problem in studies of relatively homogeneous populations, it can be a serious problem when studying the heterogeneous populations of North America. To circumvent this problem, family-based association analysis methods have been developed. One such method, called AFBAC (for AffectedFamily-BAsed Controls [39]) involves comparing the frequency distributions of marker alleles transmitted with those not transmitted from parents to an affected child [40-42]. The non-transmitted control alleles come from the same parents as the transmitted disease alleles and are thus ethnically-matched. The TDT (Transmission Disequilibrium Test) is another family-based association test, in which the observed frequency of transmission of a particular allele from heterozygous parents to an affected child is compared with the $50 \%$ expected by chance [43]. TDT is sometimes referred to as a linkage test, but it should be noted that the TDT does not detect linkage between a disease and a marker locus unless linkage disequilibrium also exits, even when families with multiple affected children are included [44, 45]. One disadvantage of family-based methods is that they are not designed to test for genotype associations. Therefore, case-control association analysis is preferable to family-based analysis if the study population is ethnically homogeneous, and any disease association initially detected with family-based methods should be followed up with case-control genotype studies in homogeneous populations.

Currently, there are two general approaches to locating susceptibility genes using linkage and association analysis. The first approach is to employ numerous uniformly-spaced, mapped marker loci to test for linkage across the entire genome (linkage genome screen). When significant linkage is found, the linked region is intensively searched for linkage disequilibrium in order to zoom in to a smaller region containing genes that can be tested for specific disease-associated variants. These genes are referred to as positional candidate genes, because they are initially located by chromosomal position and then assessed as candidates for disease susceptibility. The second approach is to go directly to analysing markers near or within known genes thought to be reasonable functional candidates for disease susceptibility, and to test these for both linkage and association (candidate gene studies). A third approach, which could be used in the not-too-distant future, will involve testing for association across the genome using very dense maps of markers (linkage disequilibrium genome screen). However, it is not clear how successful disequilibrium scans will be, particularly because the thousands of markers tested will yield many false positive signals which could be difficult to distinguish from true signals. As noted above, linkage and association are complementary methods for gene detection. Associa- tion can be used to confirm a positive linkage result but only if the marker is close enough to the disease locus for disequilibrium to occur (and even if the marker is very close, there is no guarantee that disequilibrium will exist). Linkage can also be used to confirm a positive association result, but as we will see below, strong association can occur in the absence of significant linkage.

\section{The challenges of searching for Type I diabetes genes}

There are now more than 20 putative Type I diabetes genes, most reported since late 1994 . These discoveries were fuelled by the availability of large numbers of PCR-based microsatellite markers, and of DNA from numerous families with multiple diabetic siblings suitable for linkage genome screens from repositories such as the British Diabetic Association [46] and the Human Biological Data Interchange [47]. Current diabetes susceptibility loci are listed in Table 2, together with their provisional IDDM gene symbols (assigned by the Human Gene Mapping Nomenclature Committee), their cytogenetic chromosomal region, the genetic marker that produced the strongest evidence for linkage or association with diabetes, and the key studies leading to their discovery. Rather than reviewing this list, we will focus on seven challenges or insights that emerge from our continuing efforts to understand the genetics of Type I diabetes, and will use individual susceptibility loci as examples of the discovery process.

1. Finding the region does not readily give you the gene or mechanism. More than 25 years ago, it was discovered that alleles at the human leukocyte antigen (HLA) class I $H L A-B$ locus were associated with Type I diabetes, using case-control association studies [48-50]. HLA loci were candidates for predisposition to autoimmunity because HLA molecules have a critical role in the regulation of the immune response by binding and presenting foreign or selfantigens to $\mathrm{T}$ lymphocytes. Later studies showed that HLA class II loci, including HLA-DRB1, $D Q B 1$ and $D Q A 1$, were even more strongly associated with diabetes. As a result of several genome-wide linkage screens $[61,62,73,83]$, it is now clear that the most potent diabetes-predisposing genes in the entire genome are located in the HLA region on chromosome $6 \mathrm{p} 21.3$ (these HLA region susceptibility genes are now collectively referred to as IDDM1). However, because of the extensive degree of linkage disequilibrium among the various HLA loci, it has been difficult to determine which precise locus produces diabetes susceptibility (for review, see [92]). Many studies have shown that diabetics of European ancestry have higher frequencies of $H L A-D R 3$ and $D R 4$ (variants at $D R B 1$ ). For example, $96 \%$ of Cana- 
Table 2. Putative susceptibility loci for Type I diabetes

\begin{tabular}{|c|c|c|c|}
\hline Locus & Localisation & Markers & Key references \\
\hline IDDM1 & $6 \mathrm{p} 21.3$ & $H L A-D R B 1, D Q B 1, D Q A 1$ & [48-55] \\
\hline$I D D M 2$ & $11 \mathrm{p} 15$ & INS VNTR & {$[56,57]$} \\
\hline$I D D M 3$ & $15 \mathrm{q} 26$ & D15S107 & {$[58-60]$} \\
\hline$I D D M 5$ & $6 q 25$ & $E S R$ & {$[61,63,66]$} \\
\hline IDDM6 & $18 \mathrm{q} 21$ & $J K$, D18S487 & {$[61,67-69]$} \\
\hline$I D D M 7$ & $2 q 31$ & $H O X D 8, \mathrm{D} 2 \mathrm{~S} 152$ & {$[70,71]$} \\
\hline IDDM10 & $10 \mathrm{p} 11-\mathrm{q} 11$ & D10S193 & {$[73,74]$} \\
\hline IDDM11 & $14 \mathrm{q} 24.3-\mathrm{q} 31$ & D14S67 & {$[75]$} \\
\hline IDDM12 & $2 q 33$ & CTLA4 & [76-80] \\
\hline$I D D M 13$ & $2 q 35$ & D2S164 & {$[81]$} \\
\hline IDDM14 & - & - & (unpublished) \\
\hline IDDM15 & $6 q 21$ & D6S283 & {$[82,83]$} \\
\hline Unnamed & $19 \mathrm{p} 13$ & D19S247 & [73] \\
\hline Unnamed & $19 \mathrm{q} 13$ & D19S225 & {$[73]$} \\
\hline Unnamed & Xp13-p11 & DXS1068 & {$[61,88]$} \\
\hline Unnamed & $7 \mathrm{p} 13$ & $G C K$ & [89] \\
\hline Unnamed & $12 \mathrm{q} 14-\mathrm{q} 15$ & $I F N G$ & {$[90,91]$} \\
\hline
\end{tabular}

dian Type I diabetic children had at least one of these alleles, compared with $46 \%$ of the general population [93]. However, DR4 haplotypes in diabetics were found to have a higher frequency of $D Q B 1 * 0302$ at the nearby $H L A-D Q B 1$ locus than $D R 4$ haplotypes in control subjects [51], which suggested that $D Q B 1$ rather than $D R B 1$ might be the primary diabetes susceptibility locus. Similarly, several HLA haplotypes positively associated with Type I diabetes (including $D R 4-D Q B 1^{*} 0302$ ) were found to encode an amino acid other than aspartate at position 57 of the $D Q B 1$ chain, again implying that $D Q B 1$ was the primary susceptibility locus [52]. However, an elegant study showed that DR4 haplotypes encoding both $D R B^{*} 0401$ (a subtype of $D R 4$ ) and $D Q B^{*} 0302$ were more diabetogenic than DR4 haplotypes encoding only one of these [53] - thus, $D R B 1$ and $D Q B 1$ together could confer susceptibility. The $H L A-D Q A 1$ locus also appears to be involved in susceptibility $[54,55]$. In addition to susceptibility alleles, there are also protective alleles. For example, $D R 2$ haplotypes carrying $D R B 1 * 1501$ and $D Q B 1 * 0602$ confer strong (apparently dominant) protection against diabetes. Because it is not yet known which antigens (presented with HLA to the immune system) are critical to initiating autoimmune diabetes, the mechanism by which HLA genes produce susceptibility to (or protection from) diabetes has not yet been established. One recent model is that susceptible HLA-DR and DQ molecules bind diabetogenic antigens with low affinity and allow escape from the thymus into the periphery of self-reactive $\mathrm{T}$ cells, while protective HLA molecules bind with high affinity, resulting in thymic negative selection of autoreactive T cells [94]. This model could explain the dominant effect of protective alleles. It has also been suggested that, in addition to HLA, other genes within the HLA region are associated with Type I diabetes [95-97], but these associations could be secondary to linkage disequilibrium with HLA [98-101]. Numerous linkage studies have also shown the existence of susceptibility genes in the HLA region. In 538 diabetic sibpairs, $54 \%$ shared two HLA haplotypes and only $7.3 \%$ shared zero haplotypes, both frequencies significantly different from the $25 \%$ expected [102]. From these data, one can estimate the increased risk to siblings of diabetics attributable to HLA region genes to be about 3.4 (HLA $\lambda_{\text {sib }}=$ ratio of expected to observed sharing of zero haplotypes in siblings $=0.25 / 0.073=3.4)[3]$. Because the total increase in risk to siblings is about 15 (see above), the HLA contribution to total familial clustering of diabetes is about $44 \%$ (assuming that $\lambda_{\text {sib }}$ values are multiplicative, $15 / 3.4=4.4$, and $3.4 /[3.4+4.4]=44 \%$ ). In summary, it appears that the largest genetic contribution to Type I diabetes is through $H L A-D R B, D Q B$ and $D Q A$ alleles, which confer varying degrees of susceptibility or resistance. However, after more than 25 years of study, it is still not clear how and in which combinations the HLA genes produce their predisposing or protective effects.

Over 15 years ago, significant association was detected between Type I diabetes and short alleles at a variable number tandem repeat (VNTR) marker in the $5^{\prime}$ flanking region of the insulin gene (INS) on 
chromosome $11 \mathrm{p} 15$ [56]. Susceptibility conferred by this region is now known as IDDM2. Despite intensive effort, the cause of the association with the insulin gene region is still not known. It is possible that the VNTR itself directly influences insulin gene expression [103, 104]. However, some studies showed high-risk, short alleles to be associated with increased insulin gene transcription in the pancreas [105, 106], while another study showed protective long alleles to be associated with increased transcription [107]. Subsequently, two studies showed long alleles to be associated with increased insulin expression in the thymus [108, 109]. This led to the hypothesis that higher concentrations of insulin in the developing thymus could promote the induction of immune tolerance towards insulin and thereby reduce the predisposition to diabetic autoimmunity. In summary, it appears that the $5^{\prime}$ INS VNTR could be associated with insulin transcription, but how this might modify susceptibility to Type I diabetes is still not clear. It is also possible that a polymorphism in linkage disequilibrium with the VNTR could be the functional variant conferring diabetes susceptibility.

\section{Association analysis is more powerful than linkage} analysis. The IDDM2 locus was first detected by finding association with the insulin region VNTR in unrelated patients and control subjects. Researchers, aware of the propensity of case-controls studies for creating spurious associations, sought to confirm the association by detecting evidence for linkage. However, no clear evidence could be found for increased sharing of INS region markers in diabetic sibpairs (e.g. $[41,110])$. Even the largest Type I diabetes linkage study to date (616 families [83]) could not detect strong evidence for linkage to this region (maximum lod score 0.6). However, application of family-based association analysis using AFBAC $[57,111]$ indicated that the population-based association was not spurious. The INS region studies clearly showed that significant association (linkage disequilibrium) could be detected in the absence of evidence for linkage [111]. This could seem paradoxical; however, it has been shown by simulation studies that a susceptibility gene which has a modest effect on disease risk and is common in the general population (many persons are homozygous) could be detectable by association but not by linkage analysis [110]. When linkage analysis was restricted to families in which at least one parent of the affected sibpair was heterozygous for the diabetes-associated allele, increased gene sharing in affected children could be detected $[110,112]$. In summary, it is not likely that IDDM2 would have been detected in a random linkage genome screen. Rather, it was detected by testing for association with a marker immediately adjacent to a candidate gene, insulin. It follows that important susceptibility genes have not been uncovered by current linkage screens but remain to be discovered by candidate gene studies (or possibly by very dense association genome screens).

Stated differently, association analysis is more powerful than linkage analysis for detecting common susceptibility genes of modest effect, provided that the marker is at or very near the susceptibility locus. Theoretical studies have reached the same conclusion [113]. In fact, it has been convincingly argued that the majority of susceptibility genes for genetically-complex diseases (such as Type I diabetes) will be located using the more powerful disequilibrium mapping approach [113]. Recently, we have been assessing genes involved in antiviral immune defence pathways as functional candidate genes for Type I diabetes susceptibility. To date, we have found no linkage but strong evidence for association (using family-based methods) of markers within two antiviral genes, $2^{\prime} 5^{\prime}$ oligoadenylate synthetase $(O A S, p=0.0019$ [114]) and interferon regulatory factor 2 (IRF2, $p=0.0082$ [115]). These findings suggest that common genetic variation at loci determining host response to viruses could contribute to diabetes predisposition (and indirectly support the hypothesis that viruses are involved in causing this disease). The results also show the increased power of association compared with linkage analysis when testing specific candidate genes.

3. The linkage heterogeneity problem. IDDM3 can be used to introduce what is now a familiar problem encountered in analysis of Type I diabetes and, indeed, in most multigene disorders - the problem of failure to replicate in some or all subsequent studies. IDDM3 was localised to chromosome $15 \mathrm{q} 26$ by highly suggestive evidence for linkage (lod score 2.5, affected sibpair $p$ value $=0.001$ ) using 250 multiplex families [58]. It was confirmed in two smaller independent samples of American and Danish families (affected sibpair $p=0.020$ and 0.010) [59,60], but could not be detected in a sample of Italian families [63]. To date, the two largest genome-wide linkage screens for Type I diabetes genes (published backto-back in 1998) are Concannon et al. [83], who analysed 616 American and British families in two mixed sets (Set 1: 188 families, Set 2: 428 families), and Mein et al. [73] who analysed 356 British families (250 of which were apparently also included in Concannon et al.). Evidence for linkage to IDDM3 was seen in family set 1 of Concannon et al. (which overlapped with families analysed for initial detection of IDDM3 [58]), but no evidence for linkage was found in their family set 2, nor in the families of Mein et al. What does it mean when large datasets fail to replicate linkage found in one or more smaller datasets?

In fact, even the results of the two large genome screens [73, 83] were highly inconsistent. In terms of regions with MLS $>1.5$, the only overlap between 
those studies was the HLA region (IDDM1, detected in virtually every linkage study done) and the chromosome 6q25-q27 region (IDDM5 and IDDM8). Furthermore, in those screens, large lod scores were obtained in regions that had not been detected in previous studies : MLS 3.3 at 1q42 [83] and MLS 3.4 at 16q22-q24 [73]. But ironically, neither linkage was found in both studies. This suggests that additional regions showing linkage remain to be discovered in future genome scans, but again they will be difficult to verify. Another dramatic illustration of linkage heterogeneity was provided by IDDM10. This locus was initially mapped to the centromeric region of chromosome 10 in 236 British families with MLS 2.96 [74]. Increasing the sample size to 356 families strengthened the results, to MLS 4.7 [73]. In fact, this was the strongest non-HLA linkage observed in the latter study. Conversely, using many of the same British families as Mein et al. [73] as well as numerous American families, Concannon et al. [83] found little evidence for linkage to IDDM10 (MLS 0.4). Now the question becomes what does it mean when one large dataset fails to replicate linkage found in another large dataset?

Linkage heterogeneity between datasets could be due to, firstly, sampling variation (by chance, different samples of families from the same population contain differing frequencies of various susceptibility genes; as a result, linkages to susceptibility genes with low frequency or weak effects are difficult to replicate); secondly, population genetic variation (differing frequencies of susceptibility alleles in different ethnic groups, or in unrecognised subpopulations of the study population); thirdly, population environmental variation (differing frequencies of relevant environmental factors leading to different penetrances of interacting susceptibility genotypes); fourthly, combinations of all of the above; or finally, no true linkage (false positive results in the initial report, no susceptibility gene in the region).

Non-HLA diabetes-predisposing genes tend to have weak effects on susceptibility (eg. average gene sharing in affected sibpairs is less than $60 \%$, compared with about $70 \%$ for HLA region markers), leading researchers to hold understandable concerns about the lack of power in small sample sizes. If heterogeneity were primarily due to sampling variation, then pooling families to create larger sample sizes should facilitate the detection of linkage. Conversely, if heterogeneity were primarily due to population genetic and gene-environment variation, then pooling families from a variety of ethnic backgrounds and geographic locations would enable the detection only of susceptibility genes that have the strongest effects and are found in most populations. Concannon et al. [83] studied 616 British and American families, a larger but probably more ethnically and geographically heterogeneous sample than the 356 British fam- ilies studied by Mein et al. [73]. It is of interest, therefore, that fewer large linkage signals (MLS $>1.5$ in total dataset) were detected by Concannon et al. than by Mein et al., suggesting that ethnic variation or gene-environment variation or both can negatively influence ability to detect linkage.

Finally, it should be emphasized that reported linkages need to be considered tentative until confirmed in independent studies. In other words, heterogeneity of linkage results between different datasets could be due to a false positive signal in the initial report (point No. 5 above: no susceptibility gene exists in the region). The pertinent questions here are, what constitutes statistically significant linkage in the first place, and what constitutes confirmation? There is ongoing debate about what significance level ( $p$ value) should be considered acceptable for mapping genes underlying complex traits such as Type I diabetes. As noted above, some authorities have recommended that a lod score of 3.3 (equivalent to $p$ value of about 0.00005 ) be required to claim significant linkage (to compensate for the many markers that were, or could be, examined in a whole genome screen) [37]. However, others have argued that one should not attempt to adjust $p$ values for genomewide significance, especially when genome scans have not actually been done [e.g. 116, 117]. In reality, most lod scores associated with susceptibility genes for diabetes (and many other complex diseases) have not reached 3. Indeed, if those genes confer small effects, achieving lod scores of that magnitude could be very difficult. With respect to confirmation of reported linkages, it is recognized that due to statistical fluctuations (point No. 1 above: sampling variation), replication of a true linkage could require more work than initial detection of the linkage [37]. If only a specific region is being assessed, it has been suggested that a $p$ value of 0.01 is acceptable to confirm a significant linkage [37]. Geneticists are in need of better methods (other than testing independent samples) to confirm the existence of weakly predisposing genes. We propose that one such method could be to verify putative linkages by analysis of linkage disequilibrium in isolated populations derived from a small number of founders, where disequilibrium between disease and marker loci might be stronger (we are currently investigating one such population, French Canadians, for linkage disequilibrium with putative and candidate diabetes genes). Ultimately, a region showing true linkage should yield a genetic locus having one or more variants associated with diabetes, of which at least one is a functional change that can be shown to have relevance to disease aetiology.

4. Is positional candidate mapping feasible? Once linkage to a region has been established, the next steps are to saturate the region with markers to find 
evidence of association with diabetes or to identify candidate genes in the region ("positional candidates") in order to test them for strong association with diabetes. However, this process is fraught with difficulties. For example, IDDM4 was mapped to $F G F 3$ on chromosome 11q13 by three groups [58, 61, 62] and subsequent studies showed maximal linkage at D11S1337 just proximal to FGF3, with MLS 3.9 $[59,63]$ and MLS 2.7 [64]. Thus, it is likely that this represents a true linkage. However, MLS values of at least 1.7 extended over a wide $15 \mathrm{cM}$ region [64]. It is characteristic of linkages for genes predisposing to complex disorders that true linkage peaks tend to be broader than false peaks [118], but this also makes it difficult to define a reasonable interval for intensive disequilibrium mapping. Nevertheless, significant association has been found with markers near D11S1337 and positional candidates for IDDM4 have been proposed [64, 65, 119].

Attempts to isolate IDDM5 illustrate another difficulty with the process of disequilibrium mapping. This susceptibility gene was localised near the oestrogen receptor (ESR) locus on chromosome 6q25 [61], with an MLS of 4.5 [63]. However, no candidate for IDDM5 has yet arisen. Some evidence for association was reported for one of 15 markers tested near ESR [66], but these results might not be significant after correcting $p$ values to account for the effect of multiple tests. If many markers are analysed for association (to increase the chances that one may fall very close to the actual susceptibility gene), then theoretically some correction should be made to $p$ values. However, if the true linkage disequilibrium near the disease gene is not strong, correction for multiple testing could render that disequilibrium difficult to detect.

Another problem is that evidence for association could prove as heterogeneous as evidence for linkage, for the same reasons. For example, IDDM6 has been mapped to chromosome 18q21, showing both evidence for linkage (MLS 1.6) and association $(p=0.003)$ for markers near D18S487 [68]. However, the evidence for association was highly heterogeneous, since among 1457 families with diverse ethnogeographic origins, some groups showed no association and others strong association. Furthermore, a recent study of 627 independent families showed evidence for linkage (MLS 1.2) but no evidence for association with the D18S487 region [69].

It could be more powerful to search for association using only the subset of families whose affected sibpairs show increased gene sharing (linkage) in the region of interest. For example, IDDM11 was localised to chromosome $14 \mathrm{q} 24.3-\mathrm{q} 31$ by linkage to D14S67 (lod score 4.0), but no association was found with this marker [75]. However, when association analyses were restricted to families showing linkage to the IDDM11 region (to enrich for families in which
IDDM11 was more likely to be involved), association with D14S67 was still absent but significant association was detected with D14S256, located less than 1 $\mathrm{cM}$ distal to D14S67 $(p=0.0190)$ [85]. In order to avoid confounding evidence for linkage and association (linkage disequilibrium), association analyses were conducted using only one diabetic child from each family [85]. Interestingly, this strategy of searching for association in linked families was recently used to identify the newest diabetes gene, IDDM18, located at a functional (not positional) candidate gene, the interleukin 12B (IL12B) locus on chromosome 5q33-q34 [87]. Highly significant association was found between diabetes and variants in intron 4 and the $3^{\prime}$ untranslated region of $I L 12 B$ in the subset of affected sibpairs with increased $I L 12 B$ gene sharing but not in the subset without increased IL12B gene sharing.

Positional candidate mapping of diabetes genes should not be construed as impossible, however. It is likely, though not proven, that IDDM12 on chromosome $2 \mathrm{q} 33$ is the CTLA4 (cytotoxic T lymphocyte associated-4) locus. If so, IDDM12 will be the first gene for Type I diabetes identified by positional candidate mapping, i.e. detection of linkage followed by search for maximal association with a candidate gene in the linked region. IDDM12 was mapped by linkage (MLS 3.2), and by association with CTLA4 in Italian and Spanish datasets (combined $p$ value 0.0001 ) but not in American, British or Sardinian datasets [76]. It was confirmed by demonstration of highly significant association with an $\mathrm{A} / \mathrm{G}$ (Thr/Ala) polymorphism in exon 1 of CTLA4 in 669 multiplex and 357 simplex families $(p=0.00005)$ [77]. Again, there was marked population heterogeneity for this association: Italian, Spanish, French, Mexican, and Korean samples showed significantly increased transmission of the $G$ allele to diabetics, while British, Sardinian, Chinese, and European-Americans showed little or no increased transmission of this allele. Significant increases of the $\mathrm{G}$ allele in diabetics have also been observed in case-control studies of Germans $(p=0.0001)$ [78] and Poles $(p=0.002)$ [79]. There is also evidence that diabetes predisposition is associated with homozygosity for long alleles at a CA-repeat microsatellite in the $3^{\prime}$ untranslated region of CTLA4 [120]. A recent analysis of 10 markers in and around the CTLA4 locus found significant association only with markers in a $100 \mathrm{~kb}$ interval containing this locus [80]. CTLA4 is a strong candidate gene for Type I diabetes, because it is critical in down regulation of T-cell activation [121]. In summary, the accumulated evidence strongly supports the hypothesis that CTLA4 itself is IDDM12, but the precise predisposing variant and its mechanism of action is still not clear.

While the CTLA4 story shows the feasibility of the positional-candidate approach for identifying diabetes susceptibility genes, that story has not yet ended: 
as with the insulin VNTR, there is still no direct evidence that CTLA4 influences predisposition to Type I diabetes. Given that the complete DNA sequence for any genomic region will soon be available, it will be possible to test all genes in a linked region for evidence of association. Presumably, the gene showing the strongest linkage disequilibrium will most likely be the true susceptibility locus, especially if there is no other good candidate in the region. However, actually proving that it is the true susceptibility locus will be much more challenging. A multigene disorder by definition requires combinations of genes to manifest as disease, raising the question of how one can isolate and analyse the possible biological effects of one putative susceptibility gene separately from the others. How can the actual predisposing variant at the putative locus be identified? Again, presumably that variant will be increased in diabetics, but how do we establish causality, as opposed to secondary association due to linkage disequilibrium with the true predisposing variant. The molecular biology of genetically-complex diseases promises to be orders of magnitude more difficult to unravel than that of single-locus genetic disorders.

\section{Uncommon kindreds could be relevant to common} disorders. A strategy which has shown unexpected power in the search for Type I diabetes genes is linkage analysis of large extended families with numerous affected members. Such kindreds are very uncommon and could lead to concerns that they are segregating rare mendelian forms of diabetes rather than classical Type I diabetes. However, IDDM17 was localised to chromosome $10 \mathrm{q} 25$ by strong linkage to D10S554 $(p=0.00004)$ in a large inbred Bedouin Arab extended family with 19 members having insulin-dependent autoimmune diabetes [86]. This same region of chromosome $10 \mathrm{q}$ has also shown some evidence for linkage (MLS 1.1) in 616 families with typical Type I diabetes [83]. Bedouin Arabs have a relatively low overall frequency of Type I diabetes, but tribes with multiple affected persons are not uncommon [86]. This is consistent with their high degree of inbreeding within, but not across, tribes, and suggests that IDDM17 predisposition could be due to a recessive or dose-dependent gene. Large inbred families could serendipitously illuminate the major effect of a susceptibility gene, which in a heterogeneous sample of small families displays only a minor overall effect. The success of this study should encourage researchers to attempt to locate and investigate other large multiple-affected Kindreds.

6. The next generation is gene interaction. IDDM11 was localised to chromosome 14q24.3-q31 by unusually strong evidence for linkage (lod score 4.0, affected sibpair $p=0.00001$ ) [75]. Even more unusual, though, was the finding that linkage was strongest (lod score 4.6) in the 99 families whose affected sibpairs did not have increased sharing of HLA genes (HLA sharing $>50 \%$ ). Conversely, evidence for linkage to the region was weak (lod score 0.4) in the 147 families whose affected sibpairs did have increased HLA sharing (HLA sharing $>50 \%$ ). This heterogeneity of IDDM11 linkage between families with and without increased HLA sharing was statistically significant $(p=0.009)$. These results suggested that IDDM11 predisposition operates through pathways which are biologically independent of HLA. In other words, families with strong HLA region predisposition are less likely to also carry IDDM11 predisposition (although they might), while families without strong HLA predisposition could require additional contributions from other susceptibility genes such as IDDM11. Families with less HLA sharing have also been reported to show stronger evidence of linkage to other putative diabetes genes, for example IDDM3 [58], IDDM4 [73, 122] and IDDM13 [81, 123]. Susceptibility loci demonstrating such HLA independence could interact epistatically with each other [124]. While some susceptibility loci could act biologically independent of HLA, others have been reported to show epistatic interaction with HLA, eg. IDDM2 [122]. Again, susceptibility loci displaying interaction with HLA could themselves form epistatic networks.

Testing for linkage in subsets of data (e g. stratified by HLA sharing or HLA genotype) could increase the frequency of false positive results and therefore $p$ values could require correction for multiple testing. Ironically, analysing subsets of data could also reduce the power to detect linkage, since sample size is decreased in each subset. It would therefore be preferable to use a global method that tests for linkage to one region conditional on already detected linkage in one or more other regions (such as HLA), or that simultaneously tests linkage at multiple regions. Ideally, multilocus analysis would not only increase power to detect linkage, but would also assist in determining the nature of the relation between disease loci (i.e. genetic heterogeneity versus epistasis). Such a multilocus linkage method has been recently presented and applied to data on Type 1 diabetes [125]. Results of two-locus analysis (conditioned on HLA) showed increased power to detect IDDM2 and IDDM4 (as previously reported [122]) and also produced substantial increases in MLS values at several other regions of the genome. Particularly interesting were the results of three-locus analyses (conditioned on HLA and IDDM10) showing increased MLS values on chromosomes $3,8,15$, and 21 compared with either single-locus or two-locus results [125].

The future will see intensified research and improvement in such methodologies to identify and characterise the multiple genes underlying complex diseases. One of the most important goals of genetic 
studies of diabetes is to determine which multilocus genotypes (across all susceptibility loci) create the highest risk for development of diabetes. Individuals with those genotypes would be targeted for treatment to prevent diabetes when safe and effective prophylactic therapies become available. It is possible that several prophylactic options could be available, with effectiveness depending on the exact set of predisposing genes carried by the at-risk person. Thus, the next generation of genetic studies of Type I diabetes (and other complex disorders) will involve dissection of gene-gene interactions in order to clarify which persons, by virtue of their multilocus genotype, are most susceptible to diabetes. This research will be accompanied by studies of gene-environment interaction, when the relevant non-genetic factors are more clearly understood (eg. do differences in diabetes susceptibility via antiviral defence genes relate primarily to certain types of virus?).

7. Do these genes predispose to Type I diabetes or autoimmunity? It is well known that HLA region genes are associated with many other autoimmune or immune-related disorders in addition to Type I diabetes [126]. Recent research indicates that several of the non-HLA regions linked to Type I diabetes also show linkage to other autoimmune diseases, suggesting common pathogenic pathways shared by Type I diabetes and these other disorders [127, 128]. For example, the IDDM3 region on chromosome $15 \mathrm{q} 26$ has been reported to be linked to coeliac disease $[129,130]$, the IDDM6 region on chromosome $18 \mathrm{q} 21$ has been reported to be linked to Graves disease [131] as well as multiple sclerosis and rheumatoid arthritis [69], the IDDM8 region on chromosome $6 \mathrm{q} 27$ has been reported to be linked to rheumatoid arthritis [132], the IDDM12 (CTLA4) region on chromosome $2 \mathrm{q} 33$ has been reported to be linked to coeliac disease [133, 134], Graves disease [78, 135], multiple sclerosis [136] and rheumatoid arthritis [137, 138], the IDDM16 region on chromosome $14 \mathrm{q} 32$ has been reported to be linked to multiple sclerosis [139], and the chromosome 1q42 region containing an unnamed diabetes locus has been reported to be linked to systemic lupus erythematosus [140,141] (for additional examples, see [128]). Although some of these co-localizations could be coincidental, the possibility remains that at least a few IDDM loci would be more accurately called autoimmunity susceptibility loci. The intriguing question then arises: what determines the organ/tissue specificity of the autoimmune target, and are there genes controlling this specificity (eg. genes specific to pancreatic betacell autoimmunity)? Dissecting the genetics of autoimmunity will be a difficult but fascinating endeavour.

\section{Concluding remarks}

Genes predisposing to Type I diabetes have now been provisionally assigned to more than 20 regions of the genome through linkage and association studies (Table 2). It is clear that HLA region genes collectively contribute the major susceptibility (almost half of the total increase in risk for siblings of diabetics). The remaining susceptibility genes have much lower overall contributions to diabetes risk. However, in individual persons, particular combinations of these minor genes could have strong effects on susceptibility. Clinicians would like to be able to use information from susceptibility loci to assess an individual's risk of developing diabetes, both individuals in families of Type I diabetics and in the general population. Nevertheless, much more needs to be learned in order to use the new genetic data predicatively. We must determine which of the provisional localisations are real, a difficult task due to the extensive linkage and association heterogeneity between samples studied. We must locate all of the diabetes susceptibility loci. Experience to date suggests that additional loci remain to be discovered, some by linkage analysis but most by the more powerful association (disequilibrium) methods. We must isolate the locus in each linked region that is responsible for modifying susceptibility, determine which variants increase risk (and in which ethnic groups), and elucidate the interacting gene networks that produce the strongest effects on susceptibility. At this point, we can begin to utilise the genetic information for predictive purposes. However, the ultimate goal of prediction is prevention. Designing methods for prevention will require that we also understand the mechanisms through which genetic susceptibility occurs, and how these interact with non-genetic factors (which could also be amenable to prophylactic intervention). When we can both predict who is at highest risk for Type I diabetes and prevent them from developing this devastating disease, then the challenges now faced by geneticists will be fully rewarded.

Sources. The review is based on the relevant literature published in the English language during the period 1990-2001, as well as seminal contributions prior to 1990. Most sources can be identified through PubMed searches for "genetics and Type I diabetes" or "genetics and insulin-dependent diabetes".

Acknowledgements. L. Field's diabetes research was funded by the Medical Research Council of Canada (grant MT-7910), the Juvenile Diabetes Foundation International, and the Canadian Genetic Diseases Network of the Network of Centres of Excellence programme of the Canadian and Alberta governments. L. Field was a Senior Scientist of the Alberta Heritage Foundation for Medical Research while at the University of Calgary where some of this research was done. The following contributions are gratefully acknowledged: Drs. E. Colle, H. Dean, 
J. Dupre, M. Gonthier, J. Mahon, R. McArthur, R. Rodgers, E. Ryan, D. Stephure, L. Stewart, R. Trussell, and D. Wherrett for collection of Canadian families; M. Engels, E. Swiergala, R. Tobias and J. Nagatomi for laboratory expertise; T. Magnus, M. Nelson, G. Thomson, and Z. Zhang for computing assistance; R. Hodorek for secretarial work; and all the families who generously participated in L. Field's research.

\section{References}

1. Thomson G, Robinson WP, Kuhner MK et al. (1988) Genetic heterogeneity, modes of inheritance and risk estimates for a joint study of Caucasians with insulin-dependent diabetes mellitus. Am J Hum Genet 43: 799-816

2. Spielman RS, Baker L, Zmijewski CM (1980) Gene dosage and susceptibility to insulin-dependent diabetes. Ann Hum Genet 44: 135-150

3. Risch N (1987) Assessing the role of HLA-linked and unlinked determinants of disease. Am J Hum Genet 40: 1-14

4. Warram JH, Krolewski AS, Gottlieb MS, Kahn CR (1984) Differences in risk of insulin-dependent diabetes in offspring of diabetic mothers and diabetic fathers. N Engl J Med 311: 149-152

5. Bleich D, Polak M, Eisenbarth GS, Jackson RA (1993) Decreased risk of type I diabetes in offspring of mothers who acquire diabetes during adrenarchy. Diabetes 42: 1433-1439

6. Tuomilehto J, Podar T, Tuomilehto-Wolf E, Virtala E (1995) Evidence for importance of gender and birth cohort for risk of IDDM in offspring of IDDM parents. Diabetologia 38: 975-982

7. Verge CF, Gianani R, Kawasaki E et al. (1996) Prediction on type I diabetes in first-degree relatives using a combination of insulin, GAD, and ICA512bdc/IA-2 autoantibodies. Diabetes 45: 926-933

8. Roll U, Christie MR, Fuchtenbusch M, Payton MA, Hawkes CJ, Ziegler AG (1996) Perinatal autoimmunity in offspring of diabetic parents. The German Multicenter BABY-DIAB study: detection of humoral immune responses to islet antigens in early childhood. Diabetes 45: 967-973

9. Warram JH, Krolewski AS, Kahn CR (1988) Determinants of IDDM and perinatal mortality in children of diabetic mothers. Diabetes 37: 1328-1334

10. Barnett AH, Eff C, Leslie RDG, Pyke DA (1981) Diabetes in identical twins. Diabetologia 20: 87-93

11. Olmos P, A'Hern R, Heaton DA et al. (1988) The significance of the concordance rate for Type I (insulin-dependent) diabetes in identical twins. Diabetologia 31: 747-750

12. Kumar D, Gemayel NS, Deapen D et al. (1993) North American twins with IDDM. Genetic, etiological, and clinical significance of disease concordance according to age, zygosity, and the interval after diagnosis in first twin. Diabetes 42: 1351-1363

13. Kyvik KO, Green A, Beck-Nielsen H (1995) Concordance rates of insulin dependent diabetes mellitus: a population based study of young Danish twins. BMJ 311: 913-917

14. Hawa M, Rowe R, Lan MS et al. (1997) Value of antibodies to islet protein tryosine phosphatase-like molecule in predicting type I diabetes. Diabetes 46: 1270-1275

15. Redondo MJ, Yu L, Hawa M et al. (2001) Heterogeneity of Type I diabetes: analysis of monozygotic twins in Great Britain and the United States. Diabetologia 44: 354-362
16. Fava D, Gardner S, Pyke D, Leslie RD (1998) Evidence that the age at diagnosis of IDDM is genetically determined. Diabetes Care 21: 925-929

17. Zimmet PZ, Tuomi T, Mackay IR et al. (1994) Latent autoimmune diabetes mellitus in adults (LADA): the role of antibodies to glutamic acid decarboxylase in diagnosis and prediction of insulin dependency. Diabet Med 11: 299-303

18. Zimmet P, Turner R, McCarty D, Rowley M, Mackay I (1999) Crucial points at diagnosis. Type 2 diabetes or slow type 1 diabetes. Diabetes Care 22 [Suppl 2]: B59-B64

19. Schranz DB, Bekris L, Landin-Olsson M et al. (2000) Newly diagnosed latent autoimmune diabetes in adults (LADA) is associated with low level glutamate decarboxylase (GAD65) and IA-2 autoantibodies. Diabetes Incidence Study in Sweden (DISS). Horm Metab Res 32: 133-138

20. Tuomi T, Carlsson A, Li H et al. (1999) Clinical and genetic characteristics of type 2 diabetes with and without GAD antibodies. Diabetes 48: 150-157

21. von Herrath MG, Holz A, Homann K, Oldstone MBA (1998) Role of viruses in type I diabetes. Semin Immunol 10: $87-100$

22. Levy-Marchal C, Karjalainen J, Dubois F, Karges W, Czernichow P, Dosch HM (1995) Antibodies against bovine albumin and other diabetes markers in French children. Diabetes Care 18: 1089-1094

23. Ginsberg-Fellner F, Witt ME, Fedun B et al. (1985) Diabetes mellitus and autoimmunity in patients with the congenital rubella syndrome. Rev Infect Dis 7 [Suppl 1]:S170-S176

24. Roivainen M, Knip M, Hyoty H et al. (1998) Several different enterovirus serotypes can be associated with prediabetic autoimmune episodes and onset of overt IDDM. Childhood Diabetes in Finland (DiMe) Study Group. J Med Virol 56: 74-78

25. Dahlquist GG, Ivarsson S, Lindberg B, Forsgren M (1995) Maternal enteroviral infection during pregnancy as a risk factor for childhood IDDM. A population-based casecontrol study. Diabetes 44: 408-413

26. Hiltunen M, Hyoty H, Knip M et al. (1997) Islet cell antibody seroconversion in children is temporally associated with enterovirus infections. Childhood Diabetes in Finland (DiMe) Study Group. J Infect Dis 175: 554-560

27. Leslie RDG, Atkinson MA, Notkins AL (1999) Autoantigens IA-2 and GAD in Type I (insulin-dependent) diabetes. Diabetologia 42: 3-14

28. Bingley PJ, Bonifacio E, Williams AJK, Genovese S, Bottazzo GF, Gale EAM (1997) Prediction of IDDM in the general population: strategies based on combinations of autoantibody markers. Diabetes 46: 1701-1710

29. Lindberg B, Ivarsson SA, Landin-Olsson M, Sundkvist G, Svanberg L, Lernmark A (1999) Islet autoantibodies in cord blood from children who developed Type I (insulindependent) diabetes mellitus before 15 years of age. Diabetologia 42: 181-187

30. Ziegler AG, Hummel M, Schenker M, Bonifacio E (1999) Autoantibody appearance and risk for development of childhood diabetes in offspring of parents with type 1 diabetes: the 2-year analysis of the German BABYDIAB Study. Diabetes 48: 460-468

31. Hagopian WA, Sanjeevi CB, Kockum I et al. (1995) Glutamate decarboxylase-, insulin-, and islet cell-antibodies and HLA typing to detect diabetes in a general population-based study of Swedish children. J Clin Invest 95: $1505-1511$

32. Lipton RB, Atchison J, Dorman JS et al. (1992) Genetic, immunological, and metabolic determinants of risk for 
type 1 diabetes mellitus in families. Diabet Med 9: 224-232

33. Petersen JS, Kyvik KO, Bingley PJ et al. (1997) Population based study of prevalence of islet cell autoantibodies in monozygotic and dizygotic Danish twin pairs with insulin dependent diabetes mellitus. BMJ 314: 1575-1579

34. Redondo MJ, Rewers M, Yu L et al. (1999) Genetic determination of islet cell autoimmunity in monozygotic twin, dizygotic twin, and non-twin siblings of patients with type 1 diabetes: prospective twin study. BMJ 318: 698-702

35. Wilkin T, Hoskins PJ, Armitage M et al. (1985) Value of insulin autoantibodies as serum markers for insulin-dependent diabetes mellitus. Lancet i: $480-481$

36. Verge CF, Gianani R, Yu L et al. (1995) Late progression to diabetes and evidence for chronic beta-cell autoimmunity in identical twins of patients with type I diabetes. Diabetes 44: 1176-1179

37. Lander E, Kruglyak L (1995) Genetic dissection of complex traits: guidelines for interpreting and reporting linkage results. Nat Genet 11: 241-247

38. Risch N (1990) Linkage strategies for genetically complex traits. II. The power of affected relative pairs. Am J Hum Genet 46: 229-241

39. Thomson G (1988) HLA disease associations: a model for the study of complex human genetic disorders. Annu Rev Genet 22: 31-50

40. Field LL, Fothergill-Payne C, Bertrams J, Baur MP (1986) HLA-DR effects in a large German IDDM dataset. Genet Epidemiol [Suppl 1]: 323-328

41. Field LL (1989) Genes predisposing to IDDM in multiplex families. Genet Epidemiol 6: 101-106

42. Thomson G (1995) Mapping disease genes: family based association studies. Am J Hum Genet 57: 487-498

43. Spielman RS, McGinnis RE, Ewens WJ (1993) Transmission distortion test for linkage: the insulin gene and susceptibility in insulin-dependent diabetes mellitus. Am J Hum Genet 52: 506-516

44. Sham PC, Curtis D (1995) An extended transmission/disequilibrium test (TDT) for multi-allele marker loci. Ann Hum Genet 59: 323-336

45. Spielman RS, Ewens WJ (1996) The TDT and other family-based tests for linkage disequilibrium and association. Am J Hum Genet 59: 983-989

46. Bain SC, Todd JA, Barnett AH (1990) The British Diabetic Association - Warren Repository. Autoimmunity 7: 83-85

47. Lernmark A, Ducat L, Eisenbarth G et al. (1990) Family cell lines available for research. Am J Hum Genet 47: 1028-1030

48. Singal DP, Blajchman MA (1973) Histocompatibility (HL-A) antigens, lymphocytotoxic antibodies and tissue antibodies in patients with diabetes mellitus. Diabetes 22: 429-432

49. Nerup J, Platz P, Andersen OO et al. (1974) HL-A antigens and diabetes mellitus. Lancet ii: 864-866

50. Cudworth AG, Woodrow JC (1974) Letter: HL-A antigens and diabetes mellitus. Lancet ii: 1153

51. Nepom BS, Palmer J, Kim S-J, Hansen JA, Holbeck SL, Nepom GT (1986) Specific genomic markers for the HLA-DQ subregion discriminate between DR4 + insulin-dependent diabetes and DR4 + seropositive juvenile rheumatoid arthritis. J Exp Med 164: 345-350

52. Todd JA, Bell JI, McDevitt HO (1987) HLA-DQB gene contributes to susceptibility and resistance to insulin-dependent diabetes mellitus. Nature 329: 599-604

53. Sheehy MJ, Scarf SJ, Rowe JR et al. (1989) A diabetes susceptibility HLA haplotype is best defined by a combi- nation of HLA-DR and -DQ alleles. J Clin Invest 83: $830-835$

54. Todd JA, Mijovic C, Fletcher J, Jenkins D, Bradwell AR, Barnett AH (1989) Identification of susceptibility loci for insulin-dependent diabetes mellitus by transracial gene mapping. Nature 338: 587-589

55. Khalil I, d'Auriol L, Gobet M et al. (1990) A combination of HLA-DQ beta Asp57-negative and HLA DQ alpha Arg52 confers susceptibility to insulin-dependent diabetes mellitus. J Clin Invest 85: 1315-1319

56. Bell GI, Horita S, Karam JH (1984) A polymorphic locus near the human insulin gene is associated with insulin-dependent diabetes mellitus. Diabetes 33: 176-183

57. Thomson G, Robinson WP, Kuhner MK, Joe S, Klitz W (1989) HLA and Insulin gene associations with IDDM. Genet Epidemiol 6: 155-160

58. Field LL, Tobias R, Magnus T (1994) A locus on chromosome $15 \mathrm{q} 26$ (IDDM3) produces susceptibility to insulindependent diabetes mellitus. Nat Genet 8: 189-194

59. Luo D-F, Bui MM, Muir A, Maclaren NK, Thomson G, She J-X (1995) Affected sibpair mapping of a novel susceptibility gene to insulin-dependent diabetes mellitus (IDDM8) on chromosome 6q25-q27. Am J Hum Genet 57: 911-919

60. Zamani M, Pociot F, Raeymaekers P, Nerup J, Cassiman JJ (1996) Linkage of type I diabetes to 15q26 (IDDM3) in the Danish population. Hum Genet 98: 491-496

61. Davies JL, Kawaguchi Y, Bennett ST et al. (1994) A genome-wide search for human type 1 diabetes susceptibility genes. Nature 371: 130-136

62. Hashimoto L, Habita C, Beressl JP et al. (1994) Genetic mapping of a susceptibility locus for insulin-dependent diabetes mellitus on chromosome 11q. Nature 371: 161-164

63. Luo D-F, Buzzetti R, Rotter JI et al. (1996) Confirmation of three susceptibility genes to insulin-dependent diabetes mellitus: IDDM4, IDDM5, and IDDM8. Hum Mol Genet 5: 693-698

64. Nakagawa Y, Kawaguchi Y, Twells RC et al. (1998) Fine mapping of the diabetes-susceptibility locus, IDDM4, on chromosome 11q13. Am J Hum Genet 63: 547-556

65. Eckenrode S, Marron MP, Nicholls R et al. (2000) Fine mapping of the type 1 diabetes locus (IDDM4) on chromosome $11 \mathrm{q}$ and evaluation of two candidate genes (FADD and GALN) by affected sibpair and linkage-disequilibrium analyses. Hum Genet 106: 14-18

66. Davies JL, Cucca F, Goy JV et al. (1996) Saturation multipoint linkage mapping of chromosome $6 \mathrm{q}$ in type 1 diabetes. Hum Mol Genet 5: 1071-1074

67. Hodge SE, Anderson CE, Neiswanger K et al. (1981) Close genetic linkage between diabetes mellitus and kidd blood group. Lancet ii: 893-895

68. Merriman T, Twells R, Merriman M et al. (1997) Evidence by allelic association-dependent methods for a type 1 diabetes polygene (IDDM6) on chromosome 18q21. Hum Mol Genet 6: 1003-1010

69. Merriman TR, Cordell HJ, Eaves IA et al. (2001) Suggstive evidence for association of human chromosome 18q12-q21 and its orthologue on rat and mouse chromosome 18 with several autoimmune diseases. Diabetes 50: 184-194

70. Owerbach D, Gabbay KH (1995) The HOXD8 locus (2q31) is linked to type I diabetes: Interaction with chromosome 6 and 11 disease susceptibility genes. Diabetes 44: $132-136$

71. Copeman JB, Cucca F, Hearne CM et al. (1995) Linkage disequilibrium mapping of a type 1 diabetes susceptibility 
gene (IDDM7) to chromosome 2q31-q33. Nat Genet 9: $80-85$

72. Owerbach D (2000) Physical and genetic mapping of IDDM8 on chromosome 6q27. Diabetes 49: 508-512

73. Mein CA, Esposito L, Dunn MG et al. (1998) A search for type 1 diabetes susceptibility genes in families from the United Kingdom. Nat Genet 19: 297-300

74. Reed P, Cucca F, Jenkins S et al. (1997) Evidence for a type 1 diabetes susceptibility locus (IDDM10) on human chromosome 10p11-q11. Hum Mol Genet 6: 1011-1016

75. Field LL, Tobias R, Thomson G, Plon S (1996) Susceptibility to insulin-dependent diabetes mellitus maps to a locus (IDDM11) on chromosome 14q24.3-q31. Genomics 33: $1-8$

76. Nistico L, Buzzetti R, Pritchard LE et al. (1996) The CTLA-4 gene region of chromosome $2 \mathrm{q} 33$ is linked to, and associated with, type 1 diabetes. Hum Mol Genet 5: $1075-1080$

77. Marron MP, Raffel LJ, Garchon HJ et al. (1997) Insulindependent diabetes mellitus (IDDM) is associated with CTLA4 polymorphisms in multiple ethnic groups. Hum Mol Genet 6: 1275-1282

78. Donner H, Rau H, Walfish PG et al. (1997) CTLA4 alanine-17 confers genetic susceptibility to Graves' disease and to type 1 diabetes mellitus. J Clin Endocrinol Metab 82: $143-146$

79. Krokowski M, Bodalski J, Bratek A, Machejko P, CaillatZucman S (1998) CTLA-4 gene polymorphism is associated with predisposition to IDDM in a population from central Poland. Diabetes Metab 24: 241-243

80. Marron MP, Zeidler A, Raffel LJ et al. (2000) Genetic and physical mapping of a type 1 diabetes susceptibility gene (IDDM12) to a $100-\mathrm{kb}$ phagemid artificial chromosome clone containing D2S72-CTLA4-D2S105 on chromosome 2q33. Diabetes 49: 492-499

81. Morahan G, Huang D, Tait BD, Colman PG, Harrison LC (1996) Markers on distal chromosome $2 \mathrm{q}$ linked to insulin-dependent diabetes mellitus. Science 272: 1811-1813

82. Delepine M, Pociot F, Habita C et al. (1997) Evidence of a non-MHC susceptibility locus in type I diabetes linked to HLA on chromosome 6. Am J Hum Genet 60: 174-187

83. Concannon P, Gogolin-Ewens KJ, Hinds DA et al. (1998) A second-generation screen of the human genome for susceptibility to insulin-dependent diabetes mellitus. Nat Genet 19: 292-296

84. Veijola R, Knip M, Puukka R, Reijonen H, Cox DW, Ilonen J (1996) The immunoglobulin heavy-chain variable region in insulin-dependent diabetes mellitus: affectedsib-pair analysis and association studies. Am J Hum Genet 59: 462-470

85. Field LL (2000) Type 1 diabetes. In: Bishop T, Sham P (eds) Genetic Analysis of Multifactorial Diseases. BIOS Scientific Publ., Oxford, pp 149-175

86. Verge CF, Vardi P, Babu S et al. (1998) Evidence for oligogenic inheritance of type 1 diabetes in a large Bedouin Arab family. J Clin Invest 102: 1569-1575

87. Morahan G, Huang D, Ymer S et al. (2001) Linkage disequilibrium of a type 1 diabetes susceptibility locus with a regulatory $I L 12 B$ allele. Nat Genet 27: 218-221

88. Cucca F, Goy JV, Kawaguchi Y et al. (1998) A male-female bias in type 1 diabetes and linkage to chromosome $\mathrm{Xp}$ in MHC HLA-DR3-positive patients. Nat Genet 19: 301-302

89. Rowe RE, Wapelhorst B, Bell GI, Risch N, Spielman RS, Concannon P (1995) Linkage and association between insulin-dependent diabetes mellitus (IDDM) susceptibility and markers near the glucokinase gene on chromosome 7. Nat Genet 10: 240-242

90. Awata T, Matsumoto C, Urakami T, Hagura R, Amemiya S, Kanazawa Y (1994) Association of polymorphism in the interferon gamma gene with IDDM. Diabetologia 37: $1159-1162$

91. Jahromi M, Millward A, Demaine A (2000) A CA repeat polymorphism of the IFN-ã gene is associated with susceptibility to type 1 diabetes. J Interferon Cytokine Res 20: $187-190$

92. Cucca F, Todd JA (1996) HLA susceptibility to type 1 diabetes: methods and mechanisms. In: Browning $\mathrm{MJ}$, McMichael AJ (eds) HLA and MHC: genes, molecules and function. BIOS Scientific Publ., Oxford, pp 383-406

93. Field LL, McArthur RG (1987) The genetics of susceptibility to insulin-dependent diabetes:possible new markers. Clin Invest Med 10: 437-443

94. Ridgway WM, Fathman CG (1998) The association of MHC with autoimmune diseases: understanding the pathogenesis of autoimmune diabetes. Clin Immunol Immunopathol 86: 3-10

95. Lie BA, Todd JA, Pociot F et al. (1999) The predisposition to type 1 diabetes linked to the human leukocyte antigen complex includes at least one non-class II gene. Am J Hum Genet 64: 793-800

96. Caillat-Zucman S, Bertin E, Timsit J, Boitard C, Assan R, Bach JF (1993) Protection from insulin-dependent diabetes mellitus is linked to a peptide transporter gene. Eur $\mathbf{J}$ Immunol 23: 1784-1788

97. Deng GY, Muir A, Maclaren NK, She JX (1995) Association of LMP2 and LMP7 genes within the major histocompatibility complex with insulin-dependent diabetes mellitus: population and family studies. Am J Hum Genet 56: 528-534

98. Ronningen KS, Undlien DE, Ploski R et al. (1993) Linkage disequilibrium between TAP2 variants and HLA class II alleles; no primary association between TAP2 variants and insulin-dependent diabetes mellitus. Eur J Immunol 23: $1050-1056$

99. Cucca F, Congia M, Trowsdale J, Powis SH (1994) Insulindependent diabetes mellitus and the major histocompatibility complex peptide transporters TAP1 and TAP2: no association in a population with a high disease incidence. Tissue Antigens 44: 234-240

100. Caillat-Zucman S, Daniel S, Djilali-Saiah I et al. (1995) Family study of linkage disequilibrium between TAP2 transporter and HLA class II genes. Absence of TAP2 contribution to association with insulin-dependent diabetes mellitus. Hum Immunol 44: 80-87

101. Undlien DE, Akselsen HE, Joner G et al. (1997) No independent associations of LMP2 and LMP7 polymorphisms with susceptibility to develop IDDM. Diabetes 46: 307-312

102. Payami H, Thomson G, Motro U, Louis EJ, Hudes E (1985) The affected sib method. IV. Sib trios. Ann Hum Genet 49: 303-314

103. Hammond-Kosack MCU, Dobrinski B, Lurz R, Docherty K, Kilpatrick MW (1992) The human insulin gene linked polymorphic region exhibits an altered DNA structure. Nucleic Acids Res 20: 231-236

104. Catasti P, Chen X, Moyzis RK, Bradbury EM, Gupta G (1996) Structure-function correlations of the insulinlinked polymorphic region. J Mol Biol 264: 534-545

105. Lucassen AM, Screaton GR, Julier C, Elliott TJ, Lathrop M, Bell JI (1995) Regulation of insulin gene expression by the IDDM associated, insulin locus haplotype. Hum Mol Genet 4: 501-506 
106. Bennett ST, Lucassen AM, Gough SCL et al. (1995) Susceptibility to human type 1 diabetes at IDDM2 is determined by tandem repeat variation at the insulin gene minisatellite locus. Nat Genet 9: 284-292

107. Kennedy GC, German MS, Rutter WJ (1995) The minisatellite in the diabetes susceptibility locus IDDM2 regulates insulin transcription. Nat Genet 9: 293-298

108. Vafiadis P, Bennett ST, Todd JA et al. (1997) Insulin expression in human thymus is modulated by INS VNTR alleles at the IDDM2 locus. Nat Genet 1997 15: 289-292

109. Pugliese A, Zeller M, Fernandez A Jr et al. (1997) The insulin gene is transcribed in the human thymus and transcription levels correlated with allelic variation at the INS VNTR-IDDM2 susceptibility locus for type 1 diabetes. Nat Genet 15: 293-297

110. Cox NJ, Spielman RS (1989) The insulin gene and susceptibility to IDDM. Genet Epidemiol 6: 65-69

111. Field LL (1991) Non-HLA region genes in insulin dependent diabetes mellitus. Bailliere's Clin Endocrinol Metab 5: 413-438

112. Julier C, Hyer RN, Davies J et al. (1991) Insulin-IGF2 region on chromosome $11 \mathrm{p}$ encodes a gene implicated in HLA-DR4-dependent diabetes susceptibility. Nature 354: $155-159$

113. Risch N, Merikangas K (1996) The future of genetic studies of complex human diseases. Science 273: 1516-1517

114. Field LL, Bonnevie-Nielsen V (1999) Locus for antiviral enzyme 2',5'oligoadenylate synthetase (OAS) on chromosome 12 q24 influences predisposition to Type 1 diabetes. Am J Hum Genet 65: A59 (Abstract)

115. Field LL, Pociot F, Nerup J, Bonnevie-Nielsen V (1999) Significant association between interferon regulatory factor 2 (IRF2) gene and Type I diabetes. Diabetologia 42 [Suppl 1]:A73 (Abstract)

116. Witte JS, Elston RC, Schork NJ (1996) Genetic dissection of complex traits. Nat Genet 12: 355-356

117. Curtis D (1996) Genetic dissection of complex traits. Nat Genet 12: 356-357

118. Terwilliger JD, Shannon WD, Lathrop GM et al. (1997) True and false positive peaks in genomewide scans: applications of length-based sampling to linkage mapping. Am J Hum Genet 61: 430-438

119. Twells RC, Metzker ML, Brown SD et al. (2001) The sequence and gene characterization of a $400-\mathrm{kb}$ candidate region for IDDM4 on chromosome 11q13. Genomics 72: 231-242

120. Lowe RM, Graham J, Sund G et al. (2000) The length of the CTLA-4 microsatellite (AT)n-repeat affects the risk for type 1 diabetes. Autoimmunity 32: 173-180

121. Tivol EA, Borriello F, Schweitzer AN, Lynch WP, Bluestone JA, Sharpe AH (1995) Loss of CTLA-4 leads to massive lymphoproliferation and fatal multiorgan tissue destruction, revealing a critical negative regulatory role of CTLA-4. Immunity 3: 541-547

122. Cordell HJ, Todd JA, Bennett ST, Kawaguchi Y, Farrall M (1995) Two-locus maximum lod score analysis of a multifactorial trait: joint consideration of IDDM2 and IDDM4 with IDDM1 in type 1 diabetes. Am J Hum Genet 57: 920-934

123. Fu J, Ikegami H, Kawaguchi Yet al. (1998) Association of distal chromosome $2 \mathrm{q}$ with IDDM in Japanese subjects. Diabetologia 41: 228-232
124. Field LL, Tobias R (1997) Unravelling a complex trait: the genetics of insulin-dependent diabetes mellitus. Clin Invest Med 20: 41-49

125. Cordell HJ, Wedig GC, Jacobs KB, Elston RC (2000) Multilocus linkage tests based on affected relative pairs. Am J Hum Genet 66: 1273-1286

126. Tiwari JL, Terasaki PI (1985) HLA and Disease Associations. Springer-Verlag, New York

127. Becker KG, Simon RM, Bailey-Wilson JE et al. (1998) Clustering of non-major histocompatibility complex susceptibility candidate loci in human autoimmune diseases. Proc Natl Acad Sci U S A 95: 9979-9984

128. Becker KG (1999) Comparative genetics of type 1 diabetes and autoimmune disease: common loci, common pathways? Diabetes 48: 1353-1358

129. Zhong F, McCombs CC, Olson JM et al. (1996) An autosomal screen for genes that predispose to celiac disease in the western counties of Ireland. Nat Genet 14: 329-333

130. Houlston RS, Tomlinson IP, Ford D et al. (1997) Linkage analysis of candidate regions for coeliac disease genes. Hum Mol Genet 6: 1335-1339

131. Vaidya B, Imrie H, Perros P et al. (2000) Evidence for a new Graves disease susceptibility locus at chromosome 18q21. Am J Hum Genet 66: 1710-1714

132. Myerscough A, John S, Barrett JH, Ollier WE, Worthington J (2000) Linkage of rheumatoid arthritis to insulin-dependent diabetes mellitus loci: evidence supporting a hypothesis for the existence of common autoimmune susceptibility loci. Arthritis Rheum 43: 2771-2775

133. Djilali-Saiah I, Schmitz J, Harfouch-Hammoud E, Mougenot JF, Bach JF, Caillat-Zucman S (1998) CTLA-4 gene polymorphism is associated with predisposition to coeliac disease. Gut 43: 187-189

134. Naluai AT, Nilsson S, Samuelsson L et al. (2000) The CTLA4/CD28 gene region on chromosome 2 q33 confers susceptibility to celiac disease in a way possibly distinct from that of type 1 diabetes and other chronic inflammatory disorders. Tissue Antigens 56: 350-355

135. Yanagawa T, Taniyama M, Enomoto S et al. (1997) CTLA4 gene polymorphism confers susceptibility to Graves' disease in Japanese. Thyroid 7: 843-846

136. Harbo HF, Celius EG, Vartda F, Spurkland A (1999) CTLA4 promotor and exon 1 dimorphisms in multiple sclerosis. Tissue Antigens 53: 106-110

137. Gonzalez-Escribano MF, Rodriguez R, Valenzuela A, Garcia A, Garcia-Lozano JR, Nunez-Roldan A (1999) CTLA4 polymorphisms in Spanish patients with rheumatoid arthritis. Tissue Antigens 53: 296-300

138. Seidl C, Donner H, Fischer B et al. (1998) CTLA4 codon 17 dimorphism in patients with rheumatoid arthritis. Tissue Antigens 51: 62-66

139. Sawcer S, Jones HB, Feakes R et al. (1996) A genome screen in multiple sclerosis reveals susceptibility loci on chromosome 6p21 and 17q22. Nat Genet 13: 464-468

140. Tsao BP, Cantor RM, Kalunian KC et al. (1997) Evidence for linkage of a candidate chromosome 1 region to human systemic lupus erythematosus. J Clin Invest 99: 725-731

141. Tsao BP (2000) Lupus susceptibility genes on chromosome 1. Int Rev Immunol 19: 319-334 